\title{
Tools for teen moms to reduce infant obesity: a randomized clinical trial
}

\author{
Mildred A Horodynski ${ }^{*}$, Kami Silk², Gary Hsieh³ ${ }^{3}$ Alice Hoffman ${ }^{1}$ and Mackenzie Robson ${ }^{1}$
}

\begin{abstract}
Background: Unhealthy infant feeding practices, such as a combination of formula feeding and early introduction of solids may lead to rapid or excessive weight gain in early infancy. Adolescent mothers' feeding behaviors are most directly related to infant weight gain in the first year of life. Compared to adult mothers, adolescent mothers are less knowledgeable, less responsive, more controlling, and less skilled in infant feeding, which interferes with infants' healthy growth. The Tools for Teen Moms trial aims to compare the effect of a social media intervention for low-income adolescent, first-time mothers of infants 2 months of age or younger, versus standard care on infant weight, maternal responsiveness, and feeding style and practices. The intervention is conducted during the infant's first four months of life to promote healthy transition to solids during their first year. Tools for Teen Moms is an intervention delivered via a social media platform that actively engages and coaches low-income adolescent mothers in infant-centered feeding to reduce rapid/excessive infant weight gain in the first six months of life.
\end{abstract}

Methods/Design: We describe our study protocol for a randomized control trial with an anticipated sample of 100 low-income African- American and Caucasian adolescent, first-time mothers of infants. Participants are recruited through Maternal-Infant Health Programs in four counties in Michigan, USA. Participants are randomly assigned to the intervention or the control group. The intervention provides infant feeding information to mothers via a web-based application, and includes daily behavioral challenges, text message reminders, discussion forums, and website information as a comprehensive social media strategy over 6 weeks. Participants continue to receive usual care during the intervention. Main maternal outcomes include: (a) maternal responsiveness, (b) feeding style, and (c) feeding practices. The primary infant outcome is infant weight. Data collection occurs at baseline, and when the baby is 3 and 6 months old.

Discussion: Expected outcomes will address the effectiveness of the social media intervention in helping teen mothers develop healthy infant feeding practices that contribute to reducing the risk of early onset childhood obesity.

Trial registration: Clinical Trials.Gov NCT02244424, June 24, 2014

Keywords: Infant, Obesity, Social media, Technology, Low-income population, Intervention

\section{Background}

Rapid weight gain (RWG) during infancy is one of the strongest risk factors for obesity later in childhood [1]. A growing body of evidence shows the incidence of infant obesity, especially in low-income infants, is rapidly increasing [2-6]. The first year of life is a critical period for reducing risk of obesity [7-12], particularly the first six months $[13,14]$. Rapid weight gain in the first six months of life is associated with a sharply increased risk of

\footnotetext{
* Correspondence: millie@msu.edu

${ }^{1}$ College of Nursing, Michigan State University, 1355 Bogue Street, Bott Nursing Building, East Lansing, MI 48824, USA

Full list of author information is available at the end of the article
}

obesity later in life [15-18] and subsequent health consequences [19]. Unhealthy infant feeding practices may lead to rapid or excessive weight gain in early infancy $[12,14,20]$ and a combination of formula feeding and early introduction of solids contribute to rapid/excessive weight gain [21-25]. Factors associated with rapid/excessive weight gain include socioeconomic status, maternal age, and infant feeding practices $[20,26]$, which include formula feeding, age of introduction to solids, maternal responsiveness, and overfeeding [1,27-32]. Unhealthy mother-infant feeding practices contribute to rapid/ excessive infant weight gain $[33,34]$. Adolescent mothers' 
feeding behaviors are most directly related to infant weight gain in the first year of life [31,35,36]. Compared to adult mothers, adolescent mothers are less knowledgeable [37], less responsive, more controlling, and less skilled in infant feeding [38], which interferes with infants' self-regulation, natural weight trajectory, and healthy growth during the first year of life [39], putting these infants at higher risk for developing obesity [40]. Lowincome, adolescent, first-time mothers are also less likely to engage in infant-centered feeding (shared regulation of feeding within the mother-infant dyad) characterized by maternal responsiveness [41] (MR) (positive maternal recognition and responses to infant cues), positive feeding styles [42] (FS) (maternal guided approach to infant feeding), and healthy feeding practices (FP) [43] as recommended by the American Academy of Pediatrics (AAP) [44]. Infant-centered feeding is needed to reduce rapid/ excessive gain in the first six months of life [45]. Infantcentered feeding fosters infant feeding self-regulation [46-49], which is associated with healthy growth (weight and length) and is crucial in reducing childhood obesity risk [50-52] and adverse health conditions later in life [53-56].

Few published intervention studies on the prevention or reduction of obesity in infants exist [57]. Practical early intervention strategies are needed to promote infant-centered feeding among adolescent mothers to prevent rapid/excessive infant weight gain in the first six months of life. The few studies published about the efficacy of interventions for obesity prevention in early infancy report mixed results [30,33,58-61]. One homebased study with primarily breastfed babies supported healthy infant growth through delay of introduction to solid foods [58], while a pilot education program with high income and educated participants (which consisted of five pediatrician messages and four coaching sessions by health educators) indicated a delay of solid foods with a trend in lower change in weight-for-length z-scores $[57,59]$. A double-blind, randomized educational intervention with one session on recognizing satiety cues and limiting volume of formula found no differences on weight gain, formula intake, or parental behavior [30]. Several other studies are in progress [33,61-67], but do not focus on adolescent mothers. This study proposes a highly accessible solution that addresses the unmet knowledge needs of adolescent mothers via an intervention (Tools for Teen Moms) (T4TM) to improve infantcentered feeding (MR, FS, FP) and infant growth. The proposed intervention addresses a deficit in the literature on infant-centered feeding to reduce rapid/excessive infant weight gain that exists for this high-risk population. The purpose of the study is to test a new social media intervention (T4TM) designed by the investigators. The intervention includes an educational web-application, accessible both via computers and smartphones, designed to increase infant-centered feeding through daily behavioral challenge activities, as well as additional resources related to infancy and motherhood, a discussion forum, and a messaging system for asking questions of a registered nurse. Participants receive daily cell phone text message reminders to log on to the website and complete that day's challenge.

The ubiquity of technology in adolescents' lives requires new pedagogical methods for interventions to reduce the risk of infant obesity that are adapted to the learning and information-seeking styles preferred by this population $[68,69]$. There is a dearth of outcome research on nutrition eHealth interventions targeting adolescents [68]. The ability to use technology to deliver interventions is evident: $77 \%$ of 12 to 17 -year-olds own a cell phone [70-72]. During a six month study, adolescent mothers with infants under six months of age reported seeking health information and social support from online communities, posting 16,670 times, and spending an average of 102.25 hours on these websites [73]. The Pew Survey [71] reports teens regularly go on-line (94\%), indicating this age group embraces technology and social media in their everyday lives $[74,75]$. Social media transcends space and time constraints [76], making health messages more accessible and enabling users to decide when, where, and how they want to receive information. Social media interventions have the ability to facilitate social connections and foster emotional support between adolescent mothers who may feel isolated or disconnected; however, there is a paucity of rigorously designed randomized controlled trials (RCT) of technology-based interventions in health care [77].

T4TM is the first targeted intervention delivered via a social media web-application that actively engages and coaches low-income adolescent mothers in infantcentered feeding to reduce rapid/excessive infant weight gain in the first six months of life. Our study is innovative in multiple ways: 1) it fills a significant gap in obesity research on infant-centered feeding related to MR, FS, and FP together and their contribution in infant accelerated growth and obesity [78];2) it promotes daily maternal behavior modification across six weeks for early obesity prevention [59,79]; and 3) it targets an understudied, vulnerable population (low-income, adolescent mothers) [80]. Tools for Teen Moms goes beyond Text4Baby [81], a website that provides infant feeding information to mothers via text messaging. Tools for Teen Moms includes daily behavioral challenges, text message reminders, discussion forums, and a repository of information and references as a comprehensive social media strategy. The design of T4TM differs in its use of: 1) persuasive technology guidelines for health behavior change; 2) challenges to intrinsically motivate participants 
[82] and support self-efficacy [83]; 3) public commitment and normative influence via social media streams [84]; and 4) inexpensive, easily integrated infant-centered feeding activities [82,83]. The novelty of T4TM is not only its design but also in its ability to affect one of the few potentially modifiable infant obesity risk factors [85-87]. Tools for Teen Moms expands on existing programs focused solely on nutrition via three key techniques: 1) interpreting and responding to infant cues while transitioning to solid foods; 2) providing an attentive and infant-centered authoritative feeding style; and 3) building skills to develop, implement, and sustain an infantcentered feeding plan.

\section{Aims and hypotheses}

The aim of this study is to compare the effect of a social media intervention for low-income adolescent, first-time mothers of infants 2 months of age or younger, versus standard care on infant weight, maternal responsiveness, and feeding style and practices. Adolescent mothers with infants 2 months of age or younger will be assigned randomly to a control/usual care or intervention condition.

The usual Maternal Infant Health Program (MIHP) care only condition consists of voluntary home visits (one week postpartum, six weeks, and six months) and on-going as needed visits (up to nine during the infant's first year of life) provided by a Registered Nurse (RN), Licensed Social Worker (LSW), Registered Dietician (RD), infant mental health specialist and/or paraprofessional. Maternal Infant Health Program interventions are based on participants' individualized plans of care following in-home screening assessments. Content includes a flexible plan of care with visits based on identified domains for both the mother (e.g., family planning, transportation, housing, and breastfeeding support), and the infant (e.g., monitoring infant growth). For the T4TM plus usual MIHP care condition, participants get the same usual care treatment as the control group and also receive text messages for six weeks, reminding them to view the T4TM web-application and complete the behavioral challenges. Daily challenges cycle through a pre-determined schedule and focus on: 1) maternal-infant feeding interaction (maternal responsiveness, infant temperament, feeding style); and 2) feeding practices (e.g., delay of early introduction to solids; how much to feed babies) including the feeding environment (e.g., communication with baby, sitting down to eat, turning off the television). Participants also have the option to retroactively complete challenges posted in the last week. We hypothesize:

H1: The T4TM plus MIHP (intervention group) as compared to the MIHP only (control group) will exhibit a greater proportion of infants: a) with a growth in weight that falls below the 85th percentile of the WHO (World Health Organization) growth norms at three and six months, and b) that have a z-score change $<0.67$ in weight-for-age WHO norms over time periods one to three months, and three to six months $[27,88]$.

H2: The T4TM plus MIHP (intervention group) as compared to the MIHP only (control group) will have: a) higher average maternal responsiveness scores, b) greater probability of using a positive feeding style, and c) greater average delay in introducing solid foods in keeping with AAP guidelines.

\section{Methods/Design \\ Overall study design}

This randomized, experimental, short-term, longitudinal controlled trial uses a convenience sample of low-income adolescent first-time mothers of infants from four counties in Michigan. Participants are randomly assigned to the T4TM intervention or a control group with a retention goal of $\mathrm{N}=40$ participants per group by Time 3 data collection. Data are collected when infants are 4-8 weeks of age (Time 1), 10-12 weeks of age (Time 2), and 6 months of age (Time 3 ).

\section{Development of the intervention}

The T4TM intervention was developed based on the Healthy Babies through Infant-Centered Feeding intervention curriculum [64], which provided evidence that education about infant-centered feeding had a positive impact on low-income mothers' infant feeding knowledge and self-reported feeding behaviors. Behaviors targeted in the T4TM intervention were derived from theories and empirical studies of mother-infant interaction [86,89-91]. The infant-centered feeding experience comprises maternal responsiveness (MR), feeding styles (FS), and feeding practices (FP). Maternal responsiveness is maternal behavioral sensitivity to infant cues through accurate recognition and judgment of what the infant needs [91-97]. Feeding style pertains to the mother's beliefs about and approach (authoritative, authoritarian, permissive, or uninvolved) to guiding her infant's feeding behaviors [97-101]. Feeding practices are maternal behaviors relating to what, where, how, and how often a baby is fed [99]. Maternal behaviors affect infant growth over time [102-119].

Previous research by the Principal Investigators to inform the development of T4TM challenge content, activities, and design included focus groups in which adolescent mothers identified areas of interest and need related to infant-centered feeding practices [120]. Results from two focus groups with low-income, adolescent, firsttime mothers of infants [121] $(\mathrm{N}=16)$ revealed interests in: a) lessons on infant feeding, b) learning about the proper introduction of solid food, c) how much formula babies should be receiving, and d) learning to recognize hunger and satiation cues. 


\section{Participants and recruitment}

To be eligible, a potential participant must: be lowincome ( $\leq 185 \%$ federal poverty level in the United States and eligible for MIHP services), be between 15 and 19 years of age at time of enrollment, be a first time mom, have an infant two months of age or less, be a primary caregiver who feeds her infant at least once a day, have text messaging and web access, and have had a term birth ( $37 \leq 42$ weeks, $2500 \leq 3750$ grams birth weight). If either mother or infant has been diagnosed with an eating or nutritional condition, the dyad is ineligible. Staff members from MIHP offices in four Michigan counties target mother-infant dyads, providing information about the study to recruit mothers with infants or expectant mothers to enroll in the project.

Once eligibility is established, families are contacted for the initial data collection home visit where written informed consent is obtained. We have institutional approval to conduct this trial from the University Committee on Research Involving Human Subjects from Michigan State University.

\section{Randomization}

Data collection packets are pre-randomized into either T4TM or control group, keeping the assigned group blind to the data collectors until they arrive at participants' homes to conduct the baseline data collection. Participants are randomly assigned via computer randomization procedure using Microsoft Excel, balancing groups by the four county recruitment sites.

\section{T4TM intervention}

T4TM provides a new daily challenge over six weeks, a time frame selected to provide participants with enough opportunities to form the habit of visiting the T4TM web-application daily [122,123]. Participants log onto T4TM through their cell phones (or a computer), a technological requirement for the study that does not pose an undue burden on participants, especially as low-income households use social networks more frequently than adolescents in higher-income households $[71,72]$. Participants are encouraged to engage with T4TM as frequently as they like. Frequency of use and number of challenge completion will be logged by the application. Throughout the six-week intervention, participants will receive a daily text message, containing the challenge name and the URL to open the webapplication directly through their smartphones. When the participants visit the T4TM page they will see: 1) the name of the challenge, 2) why the challenge is important, 3) tips to complete the challenge, 4) how many people have completed the daily challenge, and 5) a space to leave comments. In addition to the rotating challenges, adolescent mothers can browse T4TM for information about infant feeding, links to related topics, a discussion forum, and a place where they can receive expert advice from a RD or RN. When participants complete a daily challenge, they may click on the "I Did This" button to publicly acknowledge their accomplishment, which serves as a motivational feedback function as they observe other mothers' completion of the challenges, thereby establishing healthy feeding practices as normative for the young mothers [124]. Participants continue to receive usual MIHP care during the intervention.

\section{Procedures}

Data are obtained by trained data collectors using both self-report questionnaires and anthropometric assessment. To ensure consistency and accuracy of data collection, a half-day intensive training session was held for data collectors prior to the collection of data, to be followed by a booster session in year 2. Training consisted of a standardized training guide and protocol including review of the instruments and measurement of infant recumbent length and weight. Telephone contact and email communication occurs between the project manager and the data collector and/or supervisor to facilitate open communication and fidelity to the protocol.

Intervals for data collection reflect time points (at infant age of 4-8 weeks, 3 months, and 6 months old) that align with both infant feeding recommended milestones and the intervention duration. For example, the third data collection occurs when the infant is 6 months old, when solids foods introduction is recommended.

\section{Measures}

\section{Maternal outcomes}

Maternal responsiveness is defined as sensitivity of the behaviors of a mother to her infant's cues through expert judgment of what her infant needs [91-95]. These behaviors comprise a relationship skill set promoting mothers' accurate recognition and response to infants' feeding cues $[96,97]$. The Maternal Infant Responsiveness Instrument [125] is used to measure maternal responsiveness to infant cues; the scale is valid [126] and reliable (alpha = .83 and .87) $[41,127]$. We expect the intervention group to have higher scores than the control group.

Feeding style expresses the mother's beliefs about and approach to guiding her infant's feeding behaviors [97,98]. It also describes how (style) mothers feed their infants (authoritative, authoritarian, permissive, uninvolved) [99-101]. An adapted version of the Infant Feeding Styles Questionnaire (IFSQ) $[128,129]$ is used to measure feeding beliefs and feeding style behaviors [42,43,97-99,129,130]. The IFSQ was pretested and validated with 150 African American first-time mothers with children $\leq 2$ years of age [43]. Reliabilities for subscales range from .75 to.95 [128]. 
We expect the intervention group to score higher in the authoritative range than the control group.

Feeding practices are maternal behaviors relating to what is fed, where, how, and how often; they are essential for ensuring healthy eating habits throughout childhood [98,102-104]. The Infant Feeding Index (IFI) [131-134] identifies age-appropriate beverages and foods offered to the infant [135-138] and the appropriateness of feeding environment (i.e., support infant's self-regulation) per AAP recommendations is a valid measure $[131,133,135,136,139]$. Of primary concern is the time at which solid foods are first introduced into the infant's diet. We expect a longer average delay of introduction to solid foods that is closer to the AAP recommendation in the intervention group compared to the control group.

\section{Infant outcome}

Infant growth is the measurement of an infant's weight and length plotted over time using $z$ scores computed from the measures taken at T1 (baseline),T2, post intervention; and T3. Infant weights and lengths will be standardized as weight-for-age percentiles (WAP) and weight-for-age $z$-scores (WAZ), using WHO Anthro [140]. Relative weight gain (or loss) can then be calculated as the difference between WAZ scores at T3 and T1 [140]. Rate of growth proportional to birth weight and body composition (a weight-for-length index) will also be calculated. We expect a greater proportion of infants in the intervention group: 1a) will fall below the 85th percentile of the WHO growth norms at three and six months; and $1 \mathrm{~b}) \mathrm{z}$ score change $<0.67$ in weight-forage WHO norms over time periods one-to-three months, and three-to-six months.

The infant's weight and length is measured at all three time points to provide an objective measure of weight status. The infant is weighed in a clean diaper on an electronic scale and weighed to the nearest half ounce. Infant length is measured in the recumbent position. Digital scales are calibrated prior to weights being taken. These data will be entered into EpiInfo V3.4.3 to calculate weight-for-length $\mathrm{z}$ scores.

\section{Maternal and infant conditions that may influence outcomes}

Maternal behaviors affect infant growth over time [102-119] and are the focus within the maternal-infant feeding interaction. Several background factors also affect infant growth $[141,142]$, such as maternal knowledge [143], self-efficacy [144], and infant temperament. The Maternal Knowledge and Self-Efficacy scale [64], a 13-item knowledge scale and 7-item, 6-point Likert selfefficacy scale of dis/agreement, has been used with lowerincome mothers of infants (alpha $=.72$ to .75) [64]. The standardized Pictorial Assessment of Temperament (PAT)
[145], a 10-item tool that requires mothers to select how they would categorize their infants' reaction to everyday situations as represented by drawings, is used for this study. The PAT provides a mean score ranging from 1 to 3 [145], and demonstrates convergent validity with other infant temperament questionnaires [146]. Demographic information is collected via a self-report questionnaire, including age, race, and maternal health.

\section{Feasibility variables}

Feasibility is assessed by rates of enrollment (percent of eligible and approached adolescents), the percentages of daily challenges completed overall, and by individual participants. These data are monitored by project staff through website tracking protocols. Attrition dates and reasons are tracked on all participants enrolled in the study by the project manager. Acceptability and satisfaction are measured at time 2 data collection using a questionnaire developed by the research team that allows participants to rate the utility of the T4TM challenges and content, and give their opinions about the format, ease of use, and delivery method [64].

\section{Sample size and power calculations}

Using non-intervention levels of infant growth to determine sample size, a power analysis using a time-averaged difference (TAD) method [147] indicated a sample size of 80 participants (40 per group) would be necessary to achieve power at .80 , with a one-tailed TAD $\mathrm{p}<0.05$ over three measures and assuming a compound symmetry covariance structure with $p=0.20$. A sample of 80 is deemed adequate; it is higher than the often recommended 12 per group [148]. The primary foci of this study include assessment of: 1) the effect size of the intervention to power a larger study, 2) feasibility, 3) practicality of data collection procedures, 4) measurement adequacy, and 5) the ability to implement.

\section{Data analysis}

Outcomes (infant growth, MR, FS, FP) and maternal and infant factors at baseline (self-efficacy, knowledge, infant age, temperament, type of feeding) will be compared across intervention and control groups using t-test for continuous variables and chi-square test for categorical variables $[149,150]$. If differences are observed, the relevant variables will be treated as covariates in our postexperiment analyses [149,151,152]. All analyses will use the intention-to-treat [153] principle based on imputed data. The hypothesis regarding differences in outcomes at each follow-up T2 and T3 between intervention and control groups will be tested using the generalized estimating equation (GEE) model [154] for proportional group differences in growth over time. To explore efficacy of the intervention as assessed by MR, FS, FP, evaluated 
pre-intervention (T1), immediately post intervention (T2), and when the infant is six months old (T3). Both general linear mixed models (GLMM) [155,156], for continuous outcomes and the GEE model for logistic or Poisson regression for binary/ordinal and count outcomes will be considered.

\section{Discussion}

Our long-term goal is to reduce the risk for infant obesity through an infant-centered feeding skill-building, educational social media intervention, which is accessible and suitable for adolescents. The T4TM study will provide: 1) increased knowledge about use of social media as a platform for helping adolescent mothers of infants develop healthy infant feeding practices that will contribute to the overall health and development of the infant; 2) specific statistical measurements of the feasibility of a web application; and 3) a research-based, empiricallytested obesity prevention curriculum product for use by community programs serving low-income adolescent mothers. Thus, the study should contribute to the scientific literature by generating new knowledge of the behavioral factors that influence childhood obesity. In addition, findings from this study will be used to enhance pre-existing education and community programs that target adolescent mothers.

In summary, T4TM is a theory-based, social media intervention that has the potential to be sustainable, given that it can be implemented in existing infrastructures delivered by community-based educators and health professionals. By providing T4TM in partnership with such agencies, the potential exists to enhance programming nationwide through broad-based dissemination and may thus have important implications for early childhood programs.

\section{Abbreviations}

RWG: Rapid weight gain; MR: Maternal responsiveness; FS: Feeding styles; FP: Feeding practices; AAP: American Academy of Pediatrics; T4TM: Tools 4 Teen Moms; RCT: Randomized controlled trial; MIHP: Maternal Infant Health Program; RN: Registered Nurse; LSW: Licensed Social Worker; RD: Registered Dietician; WHO: World Health Organization; IFSQ: Infant Feeding Styles Questionnaire; IFI: Infant Feeding Index; WAP: Weight-for-age percentiles; WAZ: Weight-for-age z-scores; PAT: Pictorial Assessment of Temperament; TAD: Time-averaged difference; GEE: Generalized estimating equation; GLMM: General linear mixed models.

\section{Competing interests}

The authors declare they have no competing interests.

\section{Authors' contributions}

All authors conceived the project, contributed to the development of the clinical trial and procurement of the funding, participated in its design and coordination, and helped draft the manuscript. All authors read and approved the final manuscript.

\section{Acknowledgements}

The authors thank the four MIHP offices involved in the T4TM project for their participation and assistance. The authors thank Dr. Roger Brown, Professor, University of Wisconsin-Madison, for his contribution to the sample size and power calculations and the data analysis sections of the manuscript. The National Institute of Child Health and Development funds this trial (NIH grant number 1R21HDO75974-OIAL).

\section{Author details}

${ }^{1}$ College of Nursing, Michigan State University, 1355 Bogue Street, Bott Nursing Building, East Lansing, MI 48824, USA. ${ }^{2}$ Department of Communication, Michigan State University, 404 Wilson Road, East Lansing, MI 48824, USA. ${ }^{3}$ Department of Human Centered Design and Engineering, University of Washington, 414 Sieg Hall, Seattle, WA 98195, USA.

Received: 23 December 2014 Accepted: 2 January 2015

Published online: 21 January 2015

\section{References}

1. Baird J, Fisher D, Lucas P, Kleijnen J, Roberts H, Law C. Being big or growing fast: systematic review of size and growth in infancy and later obesity. BMJ. 2005;331:929-34.

2. Gillman M, Rifas-Shiman S, Camargo C, Berkey C, Frazier A, Rockett H, et al. Risk of overweight among adolescents who were breastfed as infants. J Am Med Assoc. 2001;16:2461-7.

3. Stettler N, Kumanyika S, Katz S, Zemel B, Stallings V. Rapid weight gain during infancy and obesity in young adulthood in a cohort of African Americans. Am J Clin Nutr. 2003;77:1374-8.

4. Polmamus B, Dalenius K, Borland E, Mackintosh H, Smith B, GrummerStrawn L. Pediatric nutrition surveillance: 2007 report. Atlanta, GA: U.S. Department of Health and Human Services, Centers for Disease Control and Prevention; 2009.

5. Polmamus B, Dalenius K, Mackintosh H, Smith B, Grummer-Strawn L. Pediatric nutrition surveillance: 2009 report. Atlanta, GA: U.S. Department of Health and Human Services, Centers for Disease Control and Prevention; 2011.

6. Ogden C, Flegal K, Carroll M, Johnson C. Prevalence and trends in overweight among US children and adolescents, 1999-2000. J Am Med Assoc. 2002;288:1728-32.

7. Barlow S. Expert committee recommendations regarding the prevention, assessment, and treatment of child and adolescent overweight and obesity: summary report. Pediatrics. 2007;120:S164-92.

8. Parsons T, Power C, Manor O. Fetal and early life growth and body mass index from birth to early adulthood in 1958 British cohort: longitudinal study. BMJ. 2003;323:1331-5.

9. Swinburn B. Success of community intervention to combat childhood obesity varies depending on the target age group. In: 11th International Conference on Obesity. Stockholm: 2010.

10. Harrington J, Nguyen V, Paulson J, Garland R, Paseuinelli L, Lewis D. Identifying the "tipping point" age for overweight pediatric patients. Clin Pediatr (Phila). 2010;49:638.

11. Toschke AM, Grote V, Koletzko B, von Kries R. Identifying children at high risk for overweight at school entry by weight gain during the first 2 years. JAMA Pediatr. 2004;158:449-52.

12. Paul IM, Bartok CJ, Downs DS, Stifter CA, Ventura AK, Birch LL. Opportunities for the primary prevention of obesity during infancy. Adv Pediatr. 2009;56:107-133.

13. Yanovski JA. Rapid weight gain during infancy as a predictor of adult obesity. Am J Clin Nutr. 2003;77:1350-1.

14. Goodell LS, Wakefield DB, Ferris AM. Rapid weight gain during the first year of life predicts obesity in 2-3 year olds from a low-income, minority population. J Community Health. 2009:34:370-5.

15. Taveras EM, Rifas-Shiman SL, Belfort MB, Kleinman KP, Oken E, Gillman MW. Weight status in the first 6 months of life and obesity at 3 years of age. Pediatrics. 2009;123:1177-83.

16. Mennella JA, Ventura AK, Beauchamp GK. Differential growth patterns among healthy infants fed protein hydrolysate or cow-milk formulas. Pediatrics. 2011;127:110-8.

17. Monasta L, Batty G, Cattaneo A, Lutje V, Ronfani L, Van Lenthe F, et al. Early-life determinants of overweight and obesity: a review of systematic reviews. Obes Rev. 2010;11:695-708.

18. Montiero P, Victoria C. Rapid growth in infancy and childhood and obesity in later life- a systematic review. Obes Rev. 2005:6:143-54.

19. Cali AM, Caprio S. Obesity in children and adolescents. J Clin Endocrinol Metab. 2008;93:531-6.

20. Ong K. Early determinants of obesity. Endocr Dev. 2010;19:53-61. 
21. Ong KK, Loos RJF. Rapid infancy weight gain and subsequent obesity: systematic reviews and hopeful suggestions. Acta Paediatr. 2007;95:904-8.

22. Hawkins SS, Cole TJ, Law C. An ecological systems approach to examining risk factors for early childhood overweight: findings from the UK Millenium Cohort Study. J Epidemiol Community Health. 2009;63:147-55.

23. Huh SY, Rifas-Shiman SL, Taveras EM, Oken E, Gillman MW. Timing of solid food introduction and risk of obesity in preschool-aged children. Pediatrics. 2011;127:e544-51.

24. Brophy S, Cooksey R, Gravenor MB, Mistry R, Thomas N, Lyons RA, et al. Risk factors for childhood obesity at age 5 : analysis of the millennium cohort study. BMC Public Health. 2009;9:467.

25. Sloan S, Gildea A, Stewart M, Sneddon H, Iwaniec D. Early weaning is related to weight and rate of weight gain in infancy. Child Care Health Dev. 2008;34:59-64

26. Preventing childhood obesity in early care and education programs: selected standards from caring for our children. [http://cfoc.nrckids.org/].

27. Ong KK, Ahmed ML, Emmett PM, Preece MA, Dunger DB. Association between postnatal catch-up growth and obesity in childhood: prospective cohort study. Br Med J. 2000;320:967.

28. Stettler N, Zemel BS, Kumanyika S, Stallings VA. Infant weight gain and childhood overweight status in a multicenter, cohort study. Pediatrics. 2002;109:194-9.

29. Dennison BA, Edmunds LS, Stratton HH, Pruzek RM. Rapid infant weight gain predicts childhood overweight. Obesity. 2006;14:491-9.

30. Kavanagh KF, Cohen RJ, Heinig MJ, Dewey KG. Educational intervention to modify bottle-feeding behaviors among formula-feeding mothers in the WIC program: impact on infant formula intake and weight gain. J Nutr Educ Behav. 2008:40:244-50

31. Worobey J, Lopez Ml, Hoffman DJ. Maternal behavior and infant weight gain in the first year. J Nutr Educ Behav. 2009;41:169-75.

32. Baughcum AE, Burklow KA, Deeks CM, Powers SW, Whitaker RC. Maternal feeding practices and childhood obesity: a focus group study of lowincome mothers. JAMA Pediatr. 1998;152:1010-4.

33. Mihrshahi S, Battistutta D, Magarey A, Daniels LA. Determinants of rapid weight gain during infancy: baseline results from the NOURISH randomised controlled trial. BMC Pediatr. 2011;11:99.

34. Karp SM, Lutenbacher M. Infant feeding practices of young mothers. MCN Am J Matern Nurs. 2011;36:98-103.

35. Fein SB, Labiner-Wolfe J, Scanlon KS, Grummer-Strawn LM. Selected complementary feeding practices and their association with maternal education. Pediatrics. 2008;122 Suppl 2:S91-7.

36. Spear $\mathrm{H}$. Breastfeeding behaviors and experiences of adolescent mothers. MCN Am J Matern Nurs. 2006;31:106-13.

37. Tamis-Lemonda CS, Shannon J, Spellman M. Low-income adolescent mothers' knowledge about domains of child development. Infant Ment Health J. 2002;23:88-103.

38. Coll CTG, Vohr BR, Hoffman J, Oh W. Maternal and environmental factors affecting developmental outcomes of infants and adolescent mothers. J Dev Behav Pediatr. 1986;7:230-6.

39. Taveras EM, Scanlon KS, Rifas-Shiman SL, Rich-Edwards JW, Gillman MW. Association of breastfeeding with maternal control of infant feeding at age 1 year. Pediatrics. 2004;144:240-5.

40. Clark HR, Goyder E, Bissel P, Blank L, Peters J. How do parents' child-feeding behaviours influence child weight? Implications for childhood obesity policy. J Public Health (Bangkok). 2007;29:132-41.

41. Drake EE, Humenick SS, Amaankwa L, Younger J, Roux G. Predictors of maternal responsiveness. J Nurs Scholarsh. 2007:39:119-25.

42. Sacco LM, Bentley ME, Carby-Shields K, Borja JB, Goldman BD. Assessment of infant feeding styles among low income African American mothers: comparing reported and observed behaviors. Appetite. 2007;49:131-40.

43. Bentley ME, Gavin L, Black M, Teti L. Infant feeding practices of low-income, African American mothers: comparing reported and observed behaviors. Appetite. 1999:49:1085-100.

44. American Academy of Pediatrics. Pediatric nutrition handbook. 5th ed. Elk Grove Village, IL: American Academy of Pediatrics; 2004.

45. Stettler N. Nature and strength of epidemiological evidence for origins of childhood and adulthood obesity in the first year of life. Int J Obes. 2007;31:1035-43.

46. Crocetti M, Dudas R, Krugman S. Parental beliefs and practices regarding early introduction of solid foods to their children. Clin Pediatr (Phila). 2004;541-547.
47. Birch LL, Fisher JO. Development of eating behaviors among children and adolescents. Pediatrics. 1998;101(3 Pt 2):539-49.

48. Birch LL, Davidson K. Family environmental factors influencing the developmental behavioral controls of food intake and childhood overweight. Pediatr Clin North Am. 2001;48:893-907.

49. Heinig MJ, Follett JR, Ishii KD, Kavanagh-Proshaska K, Cohen R, Panchula J. Barriers to compliance with infant-feeding recommendations among lowincome women. J Hum Lact. 2006;22:27-38.

50. Ariza AJ, Greenburg RS, Unger R. Childhood overweight: management approaches in young children. Pediatr Ann. 2004;33:33-8.

51. Organization WH. Population-based prevention strategies for childhood obesity. Geneva: World Health Organization; 2009.

52. McCormick DP, Sarpong K, Jordan L, Ray LA, Jain S. Infant obesity: are we ready to make this diagnosis? J Pediatr. 2010;157:15-9.

53. Services UD of H and H. Strategic Plan for NIH Obesity Research: A Report of the NIH Obesity Task Force. Washington, DC: Institutes of Health; 2011.

54. Nutrition AA of PC on. Policy statement: prevention of pediatric overweight and obesity. Pediatrics. 2003;112:30.

55. Fund TCH. Preventing pediatric diabetes: are racial disparities a factor? A children's health fund briefing. 2004.

56. Organization WH. Quantifying selected major risks to health: The world health report 2002: reducing risks, promoting a healthy life. 2002. p. 47-91.

57. Ciampa PJ, Kumar D, Barkin SL, Sanders LM, Yin HS, Perrin EM, et al. Interventions aimed at decreasing obesity in children younger than 2 years: a systematic review. Arch Pediatr Adolesc Med. 2010;164:1098-104.

58. Paul IM, Savage JS, Anzman SL, Beiler JS, Marini ME, Stokes JL, et al. Preventing obesity during infancy: a pilot study. Obesity. 2011;19:353-61.

59. Taveras EM, Blackburn K, Gillman MW, Haines J, McDonald J, Price S, et al. First steps for mommy and me: a pilot intervention to improve nutrition and physical activity behaviors of postpartum mothers and their infants. Matern Child Health J. 2011;15:1217-27.

60. Wen LM, Baur LA, Simpson JM, Rissel C, Flood VM. Effectiveness of an early intervention on infant feeding practices and "tummy time": a randomized controlled trial. Arch Pediatr Adolesc Med. 2011;165:701-7.

61. Dattilo AM, Birch L, Krebs N, Lake A, Taveras EM, Saavedra JM. Need for early interventions in the prevention of pediatric overweight: a review and upcoming directions. J Obes. 2012;2012:1-18.

62. Groner J, Skybo T, Murray-Johnson L, Schwirian P, Eneli I, Sternstein A, et al. Anticipatory guidance for prevention of childhood obesity: design of the MOMS project. Clin Pediatr (Phila). 2009;48:483-92.

63. Li R, Magadia J, Fein SB, Grummer-Strawn LM. Risk of bottle-feeding for rapid weight gain during the first year of life. Arch Pediatr Adolesc Med. 2012;166:431-6.

64. Horodynski MA, Olson B, Baker S, Brophy-Herb H, Auld G, Van Egeren L, et al. Healthy babies through infant-centered feeding protocol: an intervention targeting early childhood obesity in vulnerable populations. BMC Public Health. 2011;11:868-74.

65. Campbell K, Kesketh K, Crawford D, Salmon J, Ball K, McCallum Z. The infant feeding activity and nutrition trial (INFANT) and early intervention to prevent childhood obesity: cluster-randomized controlled trial. BMC Public Health. 2088;8:103.

66. Daniels LA, Magarey A, Battistutta D, Nicholson JM, Farrell A, Davidson G, et al. The NOURISH randomised control trial: positive feeding practices and food preferences in early childhood - a primary prevention program for childhood obesity. BMC Public Health. 2009;9:387.

67. Watt R, Tull K, Wiggins M, Kelly Y, Molloy B, Dowler E, et al. Effectiveness of a social support intervention on infant feeding practices: randomised controlled trial. J Epidemiol Community Health. 2008;63:156-62.

68. Ahern DK, Phalen JM, Le LX, Goldman RE. Childhood obesity prevention and reduction: role of eHealth. Boston, MA: Health e-Technologies Initiative; 2007.

69. Hingle M, Nichter M, Medeiros M, Grace S. Texting for health: the use of participatory methods to develop healthy lifestyle messages for teens. J Nutr Educ Behav. 2013;45:12-9.

70. The infinite dial 2011- navigating digital platforms. [http://www.edisonresearch. com/the_infinite_dial_2011/].

71. Teens and mobile phones. [http://www.pewinternet.org/2012/03/19/teenssmartphones-texting/].

72. Review: teens, smartphones, and texting. [http://www.pewinternet.org/ 2012/03/19/teens-smartphones-texting/]. 
73. Dunham P, Hurshman A, Litwin E, Gusella J, Ellsworth C, Dodd P. Computermediated social support: single young mothers as a model system. Am J Community Psychol. 1998;26:281-306.

74. Wright KB, Bell SN. Health-related support groups on the internet: linking empirical findings to social support and computer-mediated communication theory. J Health Psychol. 2003;8:39-54.

75. Chou W, Hunt YM, Beckjord EB, Moser RP, Hesse BW. Social media use in the United States: implications for health communication. J Med Internet Res. 2009;11:e48.

76. Weinberg N, Schmale J, Uken J, Wessel K. Computer-mediated support groups. Soc Work Groups. 1995;17:43-55.

77. Melnyk B. The role of technology in enhancing evidence-based practice, education, healthcare quality, and patient outcomes: a call for randomized controlled trials and comparative effectiveness research. Worldviews Evid Based Nurs. 2012;9:63-5.

78. DiSantis K, Hodges $E$, Johnson S, Risher J. The role of responsive feeding in overweight during infancy and toddlerhood: a systematic review. Int J Obes. 2011;35:480-92.

79. Whitlock EP, O'Connor EA, Williams SB, Beil TL, Lutz KW. Effectiveness of weight management interventions in children: a targeted systematic review for the USPSTF. Pediatrics. 2010;125:e396-418.

80. Wamback KA, Aaronson L, Breedlove G, Domian EW, Rojjanasrirat W, Yeh H. A randomized controlled trial of breastfeeding support and education for adolescent mothers. West J Nurs Res. 2011;33:486-505.

81. Text4Baby. [http://www.text4baby.org]

82. Deci EL, Ryan RM. Intrinsic motivation. New York, NY: Plenum Press; 1985

83. Bandura A. Social learning theory. 1st ed. Englewoods Cliffs, NJ: Prentice Hall; 1976.

84. Consolvo S, Everitt K, Smith I, Landay JA. Design requirements for technologies that encourage physical activity. In: SIGCHI Conference on Human Factors in Computing Systems. New York, NY: ;; 2006. p. 457-66.

85. Swider SM. Outcome effectiveness of community health workers: an integrative literature review. Public Health Nurs. 2002;19:11-20.

86. Cricco-Lizza R. Infant-feeding beliefs and experiences of Black women enrolled in WIC in the New York metropolitan area. Qual Health Res. 2004;14:1997-1210

87. Griffiths LJ, Smeeth L, Hawkins SS, Cole TJ, Dezateux C, Group MCSCH. Effects of infant feeding practice on weight gain from birth to 3 years. Arch Dis Child. 2009;94:577-82.

88. Ogden CL, Flegal KM. Changes in terminology for childhood overweight and obesity. Natl Health Stat Rep. 2010;25:1-5.

89. Sumner GA, Spietz A. NCAST caregiver/parent-child interaction feeding manual. Seattle, WA: NCAST Publications; 1995.

90. Alder EM, Williams FLR, Anderson AS, Forsyth S, Florey C du V, van der Velde $\mathrm{P}$. What influences the timing of the introduction of solid foods to infants? Br J Nutr. 2004;92:527-31

91. Bornstein MH, Tamis-Lemonda CS. Maternal responsiveness and infant mental abilities: specific predictive relations. Infant Behav Dev. 1997;20:283-96

92. Bornstein MH, Tamis-Lemonda CS. Maternal responsiveness and cognitive development in children. New Dir Child Adolesc Dev. 1989;43:49-61.

93. Bowlby J. Attachment and loss. 1st ed. New York, NY: Basic Books; 1969.

94. Karl D. Maternal responsiveness of socially high-risk mothers to the elicitation cues of their 7-month-old infants. J Pediatr Nurs. 1995;10:254-63.

95. Pridham K, Steward D, Thoyre S, Brown R, Brown L. Feeding skill performance in premature infants during the first year. Early Hum Dev. 2007;83:293-305.

96. Landry SH, Smith KE, Swank PR, Assel MA, Vellet S. Does early responsive parenting have a special importance for children's development or is consistency across early childhood necessary. Dev Psychol. 2001;37:387-403.

97. Patrick H, Nicklas TA, Hughes SO, Morales M. The benefits of authoritative feeding style: caregiver feeding styles and children's food consumption patterns. Appetite. 2005;44:243-9.

98. Heinzer MM. Obesity in infancy: questions, more questions, and few answers. Newborn Infant Nurs Rev. 2005;5:194-202.

99. Hughes SO, Power TG, Orlet Fischer J, Mueller S, Nicklas TA. Revisiting a neglected construct: parenting styles in a child-feeding context. Appetite. 2005:44:83-92

100. Hughes SO, Anderson CB, Power TG, Micheli N, Jaramillo S, Nicklas TA. Measuring feeding in low-income African-American and Hispanic parents. Appetite. 2006;46:215-23.

101. Hennessy E, Hughes SO, Goldberg JP, Hyatt RR, Economos CD. Permissive parental feeding behavior is associated with an increase in intake of low-nutrient-dense foods among American children living rural communities. J Acad Nutr Diet. 2012;112:142-8.

102. Savage JS, Fisher JO, Birch LL. Parental influence on eating behavior: conception to adolescence. J Law Med Ethics. 2007;35:22-34.

103. Pridham K, Schroeder M, Brown R, Clark R. The relationship of a mothers' working model of feeding to her feeding behaviour. J Adv Nurs. 2001;35:741-50.

104. Lederman SA, Akabas SR, Moore BJ, Bentley ME, Devaney B, Gillman MW, et al. Summary of the presentations at the conference on preventing childhood obesity, December 8, 2003. Pediatrics. 2004;114:1146-73.

105. Barnard KE, Bee HL, Hammond MA. Developmental changes in maternal interactions with term and preterm infants. Infant Behav Dev. 1984;7:101-13.

106. Blissett J, Farrow CV. Predictors of maternal control of feeding at 1 and 2 years of age. Int J Obes. 2007;31:1520-6.

107. Lissau I, Sørensen T. Parental neglect during childhood and increased risk of obesity in young adulthood. Lancet. 1994;343:324-47.

108. Moens E, Braet C, Soetens B. Observation of family functioning at mealtime: a comparison between families of children with and without overweight. J Pediatr Psychol. 2007;32:52-63.

109. Birch LL, Fisher JO. Mothers' child-feeding practices influence daughters' eating and weight. Am J Clin Nutr. 2000;71:1054-61.

110. Carper J, Orlet Fischer J, Birch LL. Young girls' emerging dietary restraint and disinhibition are related to parental control in child feeding. Appetite. 2000;35:121-9.

111. Fomon SJ. Feeding normal infants: rationale for recommendations. J Am Diet Assoc. 2001;101:1002-5.

112. Mentro AM, Steward DK, Garvin BJ. Infant feeding responsiveness: a conceptual analysis. J Adv Nurs. 2002;37:208-16.

113. Barnard KE. NCAST II learner manual. Seattle, WA: NCAST Publications; 1990

114. Booth CL, Lyons NB, Barnard KE. Synchrony in mother-infant interaction: a comparison of measurement methods. Child Study J. 1984;14:95-114.

115. Hodges EA, Hughes SO, Hopkinson JM. Maternal decisions about the initiation and termination of infant feeding. Appetite. 2008;50:333-9.

116. Korner AF, Chuck B, Dontchos S. Organismic determinants of spontaneous oral behavior in neonates. Child Dev. 1968;39:1145-57.

117. Crow RA. An ethological study of the development of infant feeding J Adv Nurs. 1976;2:99-109.

118. Committee on Integrating the Science of Early Childhood Development, Youth and Families Board on Children, National Research Council. From neurons to neighborhoods: The science of early childhood development. Washington, DC: National Academy Press; 2000.

119. Clark R, Hyde JS, Essex MJ, Klein MH. Length of maternity leave and quality of mother-infant interactions. Child Dev. 1997;68:364-83.

120. Horodynski MA, Olson B, Brophy-Herb H, Shirer K, Arndt MJ, Silk K. Delaying the introduction of solid foods to infants: a six-lesson curriculum for community educators. J Nutr Educ Behav. 2006;38(Supplement 1):16-7.

121. Horodynski MA, Mills KJ. The voice of low-income adolescent mothers on infant feeding. J Ext. 2014;52: http://www.joe.org/joe/2014december/rb5.php.

122. Breckler SJ, Wiggins EC. Journal of experimental social psychology. J Exp Soc Psychol. 1989;25:253-71.

123. Ronis DL, Yates JF, Kirscht JP. Attitudes, decisions, and habits as determinants of repeated behavior. In: Pratkanis AR, Breckler SJ, Greenwald AG, editors. Attitude structure and function. 1989. p. 213-39.

124. Rivis A, Sheeran P. Descriptive norms as an additional predictor in the theory of planned behaviour: a meta-analysis. Curr Psychol. 2003;22:218-33.

125. Maternal infant responsiveness instrument. [http://miriinstrument.wordpress.com/]

126. Amankwaa L, Pickler R. Measuring maternal responsiveness. ABNF J. 2007;18:4-15.

127. Amankwaa LC, Pickler RH, Boonmee J. Maternal responsiveness in mothers of preterm infants. Newborn Infant Nurs Rev. 2007;7:25-30.

128. Thompson AL, Medez MA, Borja JB, Adair LS, Zimmer CR, Bentley ME. Development and validation of the infant feeding style questionnaire. Appetite. 2009;53:210-21

129. Golan M, Crow S. Parents are key players in the prevention and treatment of weight-related problems. Nutr Rev. 2004;62:39-50.

130. Faith MS, Scanlon KS, Birch LL, Francis LA, Sherry B. Parent-child feeding strategies and their relationships to child eating and weight status. Obes Res. 2004;12:1711-22.

131. Infant feeding practices study II and its year six follow-up. [http://www.cdc. gov/ifps/]. 
132. United States Department of Agriculture. Feeding infants: a guide for use in the child nutrition programs. Alexandria, VA: Food and Nutrition Service; 2001

133. Briefel RR, Reidy K, Karwe V, Devaney B. Feeding infants and toddlers study: improvements needed in meeting infant feeding recommendations. J Am Diet Assoc. 2004;101(1 Suppl 1):s31-7.

134. Blum RE, Wei EK, Rockett HR, Langeliers JD, Leppert J, Gardner JD, et al. Validation of a food frequency questionnaire in Native American and Caucasian children 1 to 5 years of age. Matern Child Health J. 1999;3:167-72.

135. Butte N, Cobb K, Dwyer J, Graney L, Heird W, Rickard K. American Dietetic Association, Gerber Products Company: The start healthy feeding guidelines for infants and toddlers. J Am Diet Assoc. 2004;104:4420454.

136. Skinner JD, Ziegler P, Ponza M. Transitions in infants' and toddlers' beverage patterns. J Am Diet Assoc. 2004;104(1 Suppl 1):s45-50.

137. Carruth BR, Zeigler PJ, Gordon A, Barr SI. Prevalence of picky eaters among infants and toddlers and their caregivers' decisions about offering a new food. J Am Diet Assoc. 2004;104(1 Suppl 1):557-64.

138. Measuring children's height and weight accurately at home. [http://www.cdc gov/healthyweight/assessing/bmi/childrens_bmi/measuring_children.html].

139. Expanded Food and Nutrition Education Program. [http://www.csrees.usda. gov/nea/food/efnep/efnep.html].

140. WHO anthro for personal computers version 3.1.2010: software for assessing growth and development of the world's children. [http://www.who.int/ childgrowth/software/anthro_pc_manual.pdf].

141. Kumanyika S. Environmental influences on childhood obesity: ethnic and cultural influences in context. Physiol Behav. 2008;22:61-70.

142. Sameroff AJ, Fiese BH, Zeanah, Charles H J. Models of development and development risk. In: Handbook of infant mental health. 2nd ed. New York, NY: Guildford Press; 2000. p. 3-13.

143. Vukelich C, Kliman DS. Mature teenage mothers' infant growth expectations and use of child development information sources. Fam Relat. 1985;34:189-96.

144. Teti DM, Gelfand DM. Behavioral competence among mothers and infants in the first year: the mediational role of maternal self-efficacy. Child Dev. 1991;65:918-29.

145. Clarke-Steward KA, Fitzpatrick M, Allhusen V, Goldberg W. Measuring difficult temperament the easy way. J Dev Behav Pediatr. 2000;21:207-20.

146. Worobey J, Islas-Lopez M, Hoffman DJ. Predictors of infant feeding frequency by Mexican immigrant mothers. Clin Nutr. 2008;33:333-9.

147. Liu H, Wu T. Sample size calculation and power analysis of changes in mean response over time. Commun Stat Simul Comput. 2008;37:1785-98.

148. Julious SA. Sample size of 12 per group rule of thumb for a pilot study. Pharm Stat. 2005:4:287-91.

149. Zar JH. Biostatistical analysis. 2nd ed. Prentice Hall: Englewoods Cliffs, NJ; 1984.

150. Porter AC, Raudenbach SW. Analysis of covariance: its model and use in psychological research. J Couns Psychol. 1987;34:383-92.

151. Vasey MW, Thayer JF. The continuing problem of false positives in repeated measures ANOVA in psychophysiology: a multivariate solution. Psychophysiology. 1987;24:479-86.

152. Sackett DL, Richardson SW, Rosenburg W, Haynes RBH. Evidence-based medicine. New York, NY: Churchill Livingstone; 1996.

153. Little R, Yau L. Intent-to-treat analysis for longitudinal studies with drop-outs. Biometrics. 1996;52:1324-33.

154. Liang K-Y, Zeger SL. Longitudinal data analysis using generalized linear models. Biometrika. 1986;73:13-22.

155. Brown H, Prescott R. Applied mixed models in medicine. 2nd ed. West Sussex, England: John Wiley \& Sons Ltd; 2006.

156. McLean RA, Sanders WL, Stroup WW. A unified approach to mixed linear models. Am Stat. 1991:45:54-64.

\section{Submit your next manuscript to BioMed Central and take full advantage of:}

- Convenient online submission

- Thorough peer review

- No space constraints or color figure charges

- Immediate publication on acceptance

- Inclusion in PubMed, CAS, Scopus and Google Scholar

- Research which is freely available for redistribution 